\title{
1 High genetic diversity of bivalve transmissible neoplasia in the blue 2 mussel Mytilus trossulus Gould from the subarctic Sea of Okhotsk
}

\section{${ }^{* 1}$ Skazina M.A., ${ }^{2}$ Odintsova N.A., ${ }^{2}$ Maiorova M.A., ${ }^{2}$ Frolova L.T., ${ }^{1}$ Dolganova I.A., ${ }^{3}$ Regel K.V., ${ }^{1,4}$ Strelkov P.P.}

*Corresponding author, V.O., 16 line, 29, 199034, St Petersburg, Russia, m.skazina@spbu.ru

1. St Petersburg State University, V.O., 16 line, 29, St. Petersburg 199034, Russia

2. National Scientific Center of Marine Biology, Far Eastern Branch of the Russian Academy of Sciences, Palchevsky Str. 17, Vladivostok 690041, Russia

3. Institute of the Biological Problems of the North, FEB of the RAS, Portovaya Str. 18, Magadan 685000, Russia

4. Laboratory of Monitoring and Conservation of Natural Arctic Ecosystems, Murmansk Arctic State University, Kapitana Egorova 15, Murmansk 183038, Russia

Keywords: Mytilus, transmissible cancer, disseminated neoplasia, Pacific subarctic, molecular identification

\section{Abstract}

There are increasing findings of the bivalve transmissible neoplasia derived from the Pacific mussel Mytilus trossulus (MtrBTN) in populations of different Mytilus species worldwide. The Subarctic is an area where this disease has not yet been sought despite the fact that Mytilus spp. are widespread there, and $M$. trossulus itself is a boreal species. We used cytological and histological techniques to diagnose disseminated neoplasia in a sample of M. trossulus from Magadan in the subarctic Sea of Okhotsk. Neoplasia was identified in 11 of 214 mussels studied. Using mtDNA COI sequencing, we revealed genotypes identical or nearly identical to known MtrBTN ones in the hemolymph of most of the diseased mussels. Both MtrBTN evolutionary lineages have been identified, the widespread MtrBTN2, and MtrBTN1, so far only known from M. trossulus in British Columbia on the other side of the Pacific from Magadan. In addition, MtrBTN2 was represented by two common diverged mtDNA haplolineages. These conclusions have been confirmed for selected cancerous mussels by molecular cloning of COI and additional nuclear and mtDNA genes. On the background of high genetic diversity, different cancers were similar in terms of ploidy (range 4.0 - 5.8n) and nuclear to cell ratio. Our study provides the first description of neoplasia and MtrBTN in mussels from the Sea of Okhotsk and from 
the Subarctic, of both MtrBTN1 and MtrBTN2 in the same mussel population, and the first direct comparison between these transmissible cancers.

\section{Introduction}

Bivalve molluscs, like most other metazoans, suffer from various cancers (Aktipis et al. 2015). A common cancer affecting bivalves is disseminated neoplasia (DN). In the course of this disease, neoplastic hemocytes, which are rounded and have enlarged pleomorphic nuclei and an unusual cytoskeleton, replace normal hemocytes and eventually infiltrate all the organs and tissues of the mollusc (Barber 2004; Carballal et al. 2015; Burioli et al. 2019; Odintsova 2020). DN may have a high prevalence and cause considerable damage to natural and commercial bivalve populations (Bower 1989; Farley et al. 1991; Elston et al. 1992; Villalba et al. 2001). It has recently transpired that DN can be a transmissible disease, passed from one mollusc to another by physical transfer of cancerous cells (Metzger et al. 2015, 2016). It is then referred to as bivalve transmissible neoplasia (BTN).

Blue mussels of Mytilus edulis species complex are widespread in temperate and subpolar seas of both Northern (M. edulis, M. trossulus, M. galloprovincialis) and Southern (M. chilensis, M. platensis, M. planulatus, M. galloprovincialis) Hemisphere (McDonald et al. 1991; Larraín et al. 2018). DN has been found in many geographical populations of mussels (see Ciocan and Sunila 2005; Wolowicz and Sokolowski 2006; Bramwell et al. 2021 for reviews and also below), and proven to be BTN in some cases (Metzger et al. 2016; Burioli et al. 2019; Yonemitsu et al. 2019; Hammel et al. 2021; Skazina et al. 2021), though mussels may have conventional (non-transmissible) DN as well (Hammel et al. 2021). Two evolutionary lineages of blue mussel BTN, MtrBTN1 and MtrBTN2, both derived from the Pacific mussel M. trossulus, have been recognized. MtrBTN1 has been found only in M. trossulus from British Columbia (Northeast Pacific), while MtrBTN2 has been reported from numerous populations of four different species of $M$. edulis species complex worldwide, including M. trossulus from the Sea of Japan (Northwest Pacific) (see Figure 1A for details). A widespread bipolar distribution of MtrBTN2 indicates that it has spread together with infected mussels fouling ships (Yonemitsu et al. 2019; Skazina et al. 2021). MtrBTN2 can be considered as a successful invasive species of a unicellular parasitic mussel, whose host range potentially encompasses the entire M. edulis species complex.

The comparison of MtrBTN1 and MtrBTN2 is aggravated by their seemingly disjunct geographic distribution. In addition to the cancer genotype, the symptoms of this disease may depend on the genotype of the host, and the environment may play a role, too. A different degree of our knowledge of these two transmissible cancers is another aggravation. While MtrBTN2 has been extensively studied 
cytologically and histologically (Burioli et al. 2019; Hammel et al. 2021; Skazina et al. 2021), MtrBTN1 has not been examined in detail, though there are many older studies of DN in mussels from the Northeast Pacific (Farley 1969; Vassilenko and Baldwin 2014), where we now know this lineage occurs.

Since the discovery of MtrBTN in 2016, six studies have been made, in which 48 cases of this disease have been reliably documented. Only seven of them (three MtrBTN1 and four MtrBTN2) have been reported from M. trossulus, the species in which MtrBTN originated (Metzger et al. 2016; Riquet et al. 2017; Yonemitsu et al. 2019; Hammel et al. 2021; Skazina et al. 2021). This relative scarcity of studies is partly associated with a high labour intensity of the research.

Diagnosing MtrBTN is a cumbersome procedure. To prove that an animal has transmissible cancer, it should be tested for genetic chimerism, and the genotype of the cancer should be distinguished from that of the host (Riquet et al. 2017). Potentially, rapid tests for MtrBTN may be developed based on a parallel sequencing of the hemolymph, which is most affected by the disease, and the muscle tissue, which is least affected, at the COI mtDNA barcoding locus. Cancerous COI alleles do not seem to be very diverse (Yonemitsu et al. 2019; Hammel et al. 2021; Skazina et al. 2021) and have not been detected in healthy mussels, which means they should be relatively easy to identify. To note, in the four mussels with proven MtrBTN2 from the Sea of Japan, host genotypes and cancer genotypes were successfully retrieved from, respectively, the foot muscle samples and the hemolymph samples by direct COI sequencing (Skazina et al. 2021).

BTN diversity and distribution in populations of its "parental" species $M$. trossulus and in blue mussel populations from high latitudes is an important question. M. trossulus is a boreal species of Pacific origin that has recently (post-glacially) invaded the North Atlantic (Rawson and Harper 2009; Wenne et al. 2016; Laakkonen et al. 2020). The distribution of M. trossulus (as well as M. edulis) extends northwards as far as latitudes 70-80 along different oceanic coasts (Golikov et al. 1998; Feder et al. 2003; Wenne et al. 2020). All the findings of BTN in M. trossulus were from the southern populations (regions 3, 6, 8 at Figure 1A), and most of its range remaining unexplored. So far, the northernmost report of MtrBTN, (and DN) in blue mussels has been from M. trossulus in the Baltic Sea (Figure 1; Sunila 1987).

Our recent finding of BTN in M. trossulus in the Northwest Pacific (Skazina et al. 2021; Peter the Great Bay of the Sea of Japan; population 8 in Figure 1) set us thinking about the distribution and diversity of this disease along the Pacific coast of Siberia, which is discontinuously inhabited by $M$. trossulus (McDonald et al. 1991; Golikov et al. 1998). In this study, we looked for DN and BTN in $M$. trossulus mussels collected from the Sea of Okhotsk near Magadan. The annual sea surface 
temperatures in this subarctic sea are lower than in any other region where DN and BTN in blue mussels have ever been reported (Figure 1B).

\section{Materials and Methods}

For the diagnosis of DN and BTN in mussels from the Sea of Okhotsk, we used the same stepwise approach as in our previous study of BTN in the Sea of Japan (Skazina et al. 2021), with some additions. The hemolymph was analysed by flow cytometry to quantify cell fractions of increased ploidy. Selected cancerous and healthy (control) mussels were also analysed using hemocytology in order to detail hemocyte morphology and tissue histology in order to check for infiltration of neoplastic hemocytes into mussel tissues and organs and to measure the hemocyte nuclear to cell ratio (NCR). To confirm BTN, the hemolymph and the foot tissues of four cancerous mussels were genotyped separately for three loci known to be diagnostic for MtrBTN (Yonemitsu et al. 2019): nuclear elongation factor $1 \alpha$ gene $(\mathrm{EF} 1 \alpha)$, mtDNA COI and control region (CR). Allele diversity was resolved by molecular cloning. The identity of the alleles with known $M t r B T N$ lineages was assessed by comparison with cancer genotypes from previous studies (summarized in: Yonemitsu et al. 2019; Skazina et al. 2021). The mussels for these analyses were selected on the basis of preliminary results on COI genotyping with standard LCO 1490 and HCO 2198 primers (Folmer et al. 1994). To assess the reliability of $M t r B T N$ identification by direct COI sequencing, we also sequenced COI from the hemolymph and the foot tissue of all 10 mussels with DN from our previous BTN study in the Sea of Japan (Skazina et al. 2021).

\section{Sample collection and preprocessing}

Two samples of Mytilus trossulus were collected from the same littoral population at the mouth of Marchekan Creek in the Nagaev Bay within Magadan City (sampling coordinates 59³2'N; 15046’E) in July 2020 (sample M1, sample size N=180) and September 2020 (sample M2, N=34). The molluscs were transported to the laboratory within 48 hours after sampling, and were kept there in the aquarium for a few days before the experiments. Fresh hemolymph was collected from the posterior adductor and visually checked for quality (the presence of hemocytes and the absence of contamination with gametes) under an inverted microscope CKX41 (Olympus, Japan). Aliquots of hemolymph were fixed for flow cytometry, hemocytology and genetic analyses according to the previously described protocols (Skazina et al. 2021). Small pieces of foot muscle tissues were fixed in $70 \%$ ethanol for genetic studies, while small pieces of mantle, gill and hepatopancreas were fixed for histological studies- in 4\% paraformaldehyde (PFA) in PBS, pH 7.8. 


\section{DN diagnostics}

Flow cytometry procedures were performed according to Vassilenko and Baldwin, 2014 as described in detail in Skazina et al. 2021. Mussels having at least 5\% admixture of aneuploid cells among normal hemocytes in the hemolymph were classified as DN-suggested, while other mussels were classified as healthy. For all DN-suggested mussels and control healthy ones from sample M1 the diagnosis based on flow cytometry was verified by hemocytology and (or) histology.

The hemocytes were stained with TRITC-labelled phalloidin (Molecular Probes) and DAPI (Vector Laboratories) for visualization of the actin cytoskeleton and nucleus. We also used primary mouse monoclonal antibodies against anti- $\alpha$-acetylated tubulin (clone 6-11B-1, Sigma Aldrich) for detecting mitotic spindles as described in Maiorova and Odintsova, 2015. Observations and images were made using the Zeiss LSM 780 confocal laser scanning microscope.

Histological sections $5 \mu \mathrm{m}$ thick were stained with Meyer's hematoxylin-eosin as described in Farley 1969 and Usheva and Frolova 2000 and examined using the light microscopes Primo Star or Axio Imager.Z2 (Zeiss, Germany) equipped with a digital camera. For each mussel, the cell and nucleus area $\left(\mu \mathrm{m}^{2}\right)$ of at least five healthy and 30 neoplastic hemocytes randomly selected on slides was measured using AxioVision LE software (Carl Zeiss, Germany). NCR estimations were calculated as the ratios of nucleus and cell diameters recalculated from corresponding areas using formula $\mathrm{D}=$ $2 * \sqrt{A / \pi}$, where $\mathrm{D}$ is diameter and $\mathrm{A}$ is area.

\section{BTN diagnostics and phylogenetic analysis}

DNA extraction method, PCR primers for COI, CR and EF1 $\alpha$ fragments, and cycling conditions were the same as in Yonemitsu et al. 2019. Preliminary diagnoses of cancerous mussels were done by direct Sanger sequencing of COI fragments amplified, separately, from the hemolymph and from the foot tissue. Primers LCO 1490 and HCO 2189 amplify the maternally inherited female mitochondrial genome (F-mtDNA) and, potentially, also the parentally inherited male mitochondrial genome (MmtDNA) in mussels. Diverged M-mtDNA is detected only in the male gonads (Zouros 2013). Since we did not use the gonads, there was no risk of M-mtDNA amplification. Sequencing was performed using the Genetic Analyzer ABI Prism 3500xl in the Centre for Molecular and Cell Technologies of St. Petersburg State University Research Park (https://researchpark.spbu.ru/en/biomed-eng). PCR fragments of selected cancerous individuals were subjected to molecular cloning in Evrogen JSC facilities (Russia). The haplotype diversity of detected sequences was visualized as a TCS network by PopART software (Clement et al. 2002). Sequences detected only once or twice were considered as possible artefacts of the molecular cloning approach (Paabo et al. 1990; Bradley and Hillis 1997) and 
were excluded from further analyses. We also ignored variation in the polyA region of CR because polymerases may generate artefacts in mononucleotide regions (Clarke et al. 2001). Mussels studied by all three loci were used in the phylogenetic analysis. Maximum likelihood phylogenetic trees were created using parameters as in Yonemitsu et al. 2019 on the basis of MUSCLE alignments of newly obtained sequences from cancerous individuals along with collections of MtrBTN-infected mussels studied by similar methods from Yonemitsu et al. 2019 and Skazina et al. 2021. Generation and visualization of alignments and trees were done in MEGA X software (Kumar et al. 2018).

In this study, we used allele nomenclature from Yonemitsu et al. 2019 and Skazina et al. 2021 for alleles detected in those studies. Newly discovered alleles were designated with the locus name and sequential number (e.g. COI-9), unless they were very similar to known cancer alleles, differing from them only by one or two substitutions. For such alleles, the original names were retained, and a sequential number was added (e.g. COI-U1 for an allele differing by one SNP from MtrBTN1 specific COI-U).

\section{Analysis of the Sea of Japan collections}

In our previous study of mussels from the Gaydamak population (sample J), 10 mussels were identified as cancerous by flow cytometry. Foot and hemolymph samples of four of these mussels plus the corresponding samples of two healthy ones were subjected to genotyping at COI, CR and EF1 $\alpha$ and molecular cloning at CR and EF1 $\alpha$ (Skazina et al. 2021). In this study we genotyped the remaining six cancerous mussels from the Gaydamak collection at COI using the procedures described above.

\section{Results}

\section{DN diagnostics}

Three distinct patterns were detected in the hemolymph of the studied mussels with the use of flow cytometry. (1) Most individuals had only one major diploid peak on the fluorescence histograms, sometimes with a minor admixture of tetraploid cells $(<5 \%)$, and two cell types on the FSC-A/SSC-A dot plots, which were interpreted as normal hemocytes, granulocytes and agranulocytes (Figure 2A). These mussels were classified as healthy. (2) Nine individuals (M1-3, M1-25, M1-42, M1-96, M1-105, M1-111, M1-136, M1-162, M1-167) had an additional cell population, corresponding to aneuploid hemocytes with a higher DNA content (Figure 2C, D). The ploidy of these cells, calculated relatively to the $2 \mathrm{n}$ peak, ranged from 4.0 to 5.8 in different mussels and their proportion in hemolymph ranged from 15 to 97\% (Table 1). (3) Two individuals (M1-95 and M2-22) had so few normal hemocytes 
$(\sim 1 \%)$ that the ploidy of aneuploid ones could not be estimated accurately (Figure 2B). Individuals with the second and the third pattern were classified as DN-suggested.

Table 1. Ploidy of aneuploid hemocytes, aneuploid cell rate and the COI-based BTN diagnosis of cancerous and healthy (control) mussels from the Sea of Okhotsk and the Sea of Japan. The relative ploidy of an aneuploid peak ("Ploidy") is not given for mussels with deficiency of normal hemocytes. "Hemolymph genotype" and "Foot genotype" represent the COI genotypes detected by direct sequencing of DNA from the corresponding tissues. The mussels were classified into the following categories: "Healthy" (less than 5\% aneuploid cells), "No BTN" (cancerous mussels lacking known MtrBTN alleles and signs of genetic chimerism), "BTN1" and "BTN2" (cancerous mussels with alleles of the corresponding MtrBTN lineage). Mussels, for which the diagnosis was confirmed by molecular cloning (Skazina et al. 2021; this study), are marked with asterisks.

\begin{tabular}{|c|c|c|c|c|c|}
\hline ID & Ploidy & Aneuploid cells rate & $\begin{array}{l}\text { Hemolymph } \\
\text { genotype }\end{array}$ & Foot genotype & BTN diagnosis \\
\hline M2-22* & NA & $99 \%$ & COI-U1 & COI-U1 & BTN1 \\
\hline M1-95* & NA & $99 \%$ & COI-U1 & COI-9 & BTN1 \\
\hline M1-136 & 5.5 & $97 \%$ & COI-1 & COI-11 & BTN2 \\
\hline M1-105* & 5.3 & $94 \%$ & COI-2 & COI-12 & BTN2 \\
\hline M1-111 & 4.8 & $94 \%$ & COI-2 & COI-13 & BTN2 \\
\hline M1-167 & 4.0 & $85 \%$ & COI-12 & COI-12 & No BTN \\
\hline M1-162* & 5.5 & $57 \%$ & COI-1 & COI-8 & BTN2 \\
\hline M1-96 & 4.9 & $45 \%$ & COI-14 & COI-14 & No BTN \\
\hline M1-3 & 5.8 & $24 \%$ & $\mathrm{COI}-2$ & COI-11 & BTN2 \\
\hline M1-25 & 4.5 & $20 \%$ & COI-U1 & COI-11 & BTN1 \\
\hline M1-42 & 5.8 & $15 \%$ & COI-1 & COI-12 & BTN2 \\
\hline $\mathrm{J} 1$ & NA & $98 \%$ & COI-2 & COI-7 & BTN2 \\
\hline J149 & 4.3 & $94 \%$ & COI-2 & COI-12 & BTN2 \\
\hline $\mathrm{J} 226$ & 4.6 & $93 \%$ & COI-2 & COI-10 & BTN2 \\
\hline
\end{tabular}




\begin{tabular}{|c|c|c|c|c|c|}
\hline $\mathrm{J} 161 *$ & 4.5 & $91 \%$ & COI-1 & COI-5 & BTN2 \\
\hline $\mathrm{J} 181 *$ & 47 & $80 \%$ & COI-2 & COI-6 & BTN2 \\
\hline $\mathrm{J} 54 *$ & 4.8 & $44 \%$ & COI-1 & COI-3 & BTN2 \\
\hline $\mathrm{J} 111 *$ & 4.9 & $26 \%$ & COI-2 & COI-4 & BTN2 \\
\hline $\mathrm{J} 150$ & 4.9 & $12 \%$ & COI-7 & COI-7 & No BTN \\
\hline $\mathrm{J} 162$ & 5.2 & $5 \%$ & COI-4 & COI-4 & No BTN \\
\hline $\mathrm{J} 178$ & 5.1 & $5 \%$ & COI-6 & COI-6 & No BTN \\
\hline $\mathrm{J} 17 *$ & - & $0 \%$ & COI-7 & COI-7 & healthy \\
\hline $\mathrm{J} 38 *$ & 4.0 & $3 \%$ & COI-8 & COI-8 & healthy \\
\hline
\end{tabular}

199 Some differences in the hemolymph cell content were revealed between DN-suggested mussels 200 (Supplementary Figure S1A-D) and control healthy ones (Supplementary Figure S1E, F) with the use of hemocytology. DN-suggested mussels had, in addition to normal hemocytes, also non-adherent hemocytes with enlarged pleomorphic nuclei and anomalous actin cytoskeleton. Tubulin staining did not reveal any mitotic activity in the hemolymph of any mussel.

204

205

206

Infiltration of neoplastic hemocytes with enlarged nuclei and basophilic cytoplasm into tissues was observed at the histological slides of the DN-suggested mussels (all DN-suggested mussels were examined in this respect except M2-22, M1-42 and M1-136) (Figure 3). The cell size and the nucleus size of healthy hemocytes were similar in different individuals. The characteristics of neoplastic hemocytes were also similar, with one exception. In M1-96, the size of the neoplastic hemocytes was noticeably smaller than in other individuals (by 23\%), and so was the size of the nuclei (by $30 \%$ ). The NCRs of neoplastic hemocytes were about twice as large as those of normal hemocytes (1.8 to 2.1 times larger in different mussels; the difference was the smallest in M1-96) (Table 2, Supplementary Figure S2). A few mitotic figures in neoplastic hemocytes were detected at all histological slides of the studied cancerous mussels.

To sum up, DN was suggested for 11 mussels out of the 214 mussels studied by flow cytometry (5.1\% of the sample). This diagnosis was confirmed by hemocytology and (or) histology for all cancerous mussels, except M2-22, which was not studied by these methods. 
217 Table 2. Morphometric characteristics of the neoplastic and the healthy hemocytes of cancerous

218 mussels. Mean values, ranges and standard deviations (SD) of cell and nucleus diameter in $\mu \mathrm{m}$ and

219 NCR are provided. For mussels with cancerous COI alleles MtrBTN lineage is indicated in the left 220 column.

\begin{tabular}{|c|c|c|c|c|c|c|c|c|c|c|c|}
\hline Individual & $\begin{array}{l}\text { Cell } \\
\text { type }\end{array}$ & $\mathrm{N}$ cells & $\begin{array}{c}\text { Cell } \\
\text { diameter }\end{array}$ & $\mathrm{SD}$ & Range & $\begin{array}{l}\text { Nucleus } \\
\text { diameter }\end{array}$ & SD & Range & NCR & $\mathrm{SD}$ & Range \\
\hline \multirow{2}{*}{$\begin{array}{l}\text { M1-3 } \\
\text { BTN2 }\end{array}$} & cancer & 30 & 6.6 & 0.55 & $5.66-7.91$ & 5.18 & 0.53 & $4.38-6.52$ & 0.78 & 0.05 & $0.7-0.88$ \\
\hline & healthy & 5 & 8.22 & 1.5 & $6.54-10.53$ & 3.15 & 0.22 & $2.85-3.42$ & 0.39 & 0.08 & $0.31-0.52$ \\
\hline \multirow{2}{*}{$\begin{array}{l}\text { M1-25 } \\
\text { BTN1 }\end{array}$} & cancer & 50 & 6.9 & 0.93 & $5.15-9.59$ & 5.29 & 0.63 & $4.11-6.89$ & 0.77 & 0.05 & $0.68-0.87$ \\
\hline & healthy & 8 & 8.4 & 0.84 & $6.96-9.67$ & 3.01 & 0.16 & $2.78-3.23$ & 0.36 & 0.03 & $0.32-0.40$ \\
\hline \multirow{2}{*}{$\begin{array}{l}\text { M1-95 } \\
\text { BTN1 }\end{array}$} & cancer & 50 & 6.58 & 0.64 & $5.26-7.64$ & 5.05 & 0.54 & 4.03-5.9 & 0.77 & 0.04 & $0.66-0.87$ \\
\hline & healthy & 16 & 7.91 & 0.9 & $6.84-10.71$ & 2.98 & 0.29 & $2.57-3.4$ & 0.38 & 0.05 & $0.24-0.44$ \\
\hline \multirow{2}{*}{ M1-96 } & cancer & 30 & 5.4 & 0.68 & $4.34-6.73$ & 3.73 & 0.44 & $3.14-4.48$ & 0.69 & 0.09 & $0.51-0.81$ \\
\hline & healthy & 6 & 7.89 & 1.30 & $6.38-9.65$ & 3.05 & 0.27 & $2.61-3.36$ & 0.39 & 0.07 & $0.32-0.49$ \\
\hline \multirow{2}{*}{$\begin{array}{c}\text { M1-105 } \\
\text { BTN2 }\end{array}$} & cancer & 50 & 6,91 & 0.63 & $5.61-8.21$ & 5.25 & 0.61 & $4.3-6.56$ & 0.76 & 0.06 & $0.64-0.88$ \\
\hline & healthy & 7 & 7.96 & 1.36 & $6.45-10.12$ & 3.05 & 0.26 & $2.53-3.39$ & 0.39 & 0.07 & $0.31-0.51$ \\
\hline \multirow{2}{*}{$\begin{array}{l}\text { M1-111 } \\
\text { BTN2 }\end{array}$} & cancer & 50 & 6,89 & 0.77 & $5.77-8.36$ & 5.07 & 0.66 & $4.09-6.5$ & 0.74 & 0.06 & $0.55-0.83$ \\
\hline & healthy & 7 & 7.77 & 0.89 & $5.97-8.45$ & 2.96 & 0.4 & $2.39-3.49$ & 0.38 & 0.06 & $0.3-0.48$ \\
\hline \multirow{2}{*}{$\begin{array}{l}\text { M1-162 } \\
\text { BTN2 }\end{array}$} & cancer & 50 & 7.66 & 0.83 & $6.39-9.36$ & 5.63 & 0.53 & $4.81-6.9$ & 0.73 & 0.06 & $0.61-0.92$ \\
\hline & healthy & 11 & 7.51 & 1.12 & $6.17-9.41$ & 2.97 & 0.47 & $2.13-3.74$ & 0.4 & 0.05 & $0.33-0.5$ \\
\hline \multirow{2}{*}{ M1-167 } & cancer & 50 & 7.19 & 0,62 & $6.05-8.76$ & 5.53 & 0,53 & $4.71-6.99$ & 0.77 & 0.04 & $0.72-0.85$ \\
\hline & healthy & 11 & 7.24 & 0.75 & $6.04-8.66$ & 2.94 & 0.31 & $2.53-3.47$ & 0.41 & 0.06 & $0.34-0.52$ \\
\hline
\end{tabular}

221 BTN diagnostics

\section{Direct COI sequencing}

223 Results of the COI genotyping of the hemolymph and the foot tissues of 11 cancerous mussels from

224 Magadan, 10 cancerous mussels and two healthy control mussels from the Sea of Japan are provided in

225 Table 1, 2 and Supplementary Figure S3. Visual inspection of the chromatograms revealed the

226 following three patterns. (1) Distinct sequences in different tissues (M1-95, M1-105, M1-111, M1-136,

227 J1, J149, J226). (2) Overlapping peaks ("piggybacks") in multiple positions on chromatograms from 
the hemolymph, from the foot or from both tissues (M1-3, M1-25, M1-42, M1-162, J54, J111, J161, J181) (Supplementary Figure S3). This pattern was interpreted as a mixture of two different sequences, a cancerous one with more pronounced peaks in the hemolymph than in the foot and a host one with more pronounced peaks in the foot tissues (see Supplementary Figure S3 capture for more explanations). (3) Identical sequences in both tissues with no signs of heteroplasmy (the rest of mussels). In terms of the rate of aneuploid cells, all mussels with the first pattern were severely diseased ( $>93 \%$ of aneuploid cells), while those with the second pattern were moderately to severely diseased (15-91\%). The third group was very heterogeneous and included a severely diseased M2-22 (99\%), moderately diseased M1-167 and M1-96 (85\% and 45\% respectively), slightly diseased J150, $\mathrm{J} 162$ and $\mathrm{J} 178$ (5-12\%) and control healthy mussels J17 and J38 (Table 1).

The comparison of the nucleotide sequences detected in newly studied mussels (not considering six previously genotyped mussels from $\mathrm{J}$ sample) with the collection of known MtrBTN genotypes revealed alleles characteristic of $M t r B T N 2$ (COI-1 or COI-2) in the hemolymph of nine mussels including six from Magadan. Further, a COI-U1 allele differing by 1 SNP from the unique U allele of MtrBTN1 lineage was revealed in the hemolymph of M1-95, M1-25 and M2-22. The same COI-U1 allele was detected in a homoplasmic state in the foot of the heavily infected M2-22 individual. The other alleles identified in our study differed by 2-12 substitutions from the known MtrBTN alleles and by 3-11 substitutions from each other. They were most probably the alleles of the host. No known cancer alleles and no signs of genetic chimerism were revealed in M1-96 and M1-167 individuals, which had a moderate rate of aneuploid cells, and in J150, J162 and J178 individuals, which has a low rate of aneuploid cells $<15 \%$ (Table 1 ).

Ploidy and mean NCR of neoplastic hemocytes from mussels collected near Magadan marked by different BTN COI genotypes were as follows: MtrBTN2 with COI-1 (ploidy range 5.5-5.8n; NCR 0.73), MtrBTN2 with COI-2 (4.8-5.8n; NCR range 0.74-0.78), MtrBTN1 with COI-U1 (4.5n; 0.77), M1-96 (4.9n; 0.69), M1-167 (4.0n; 0.77) (Table 1, 2; Supplementary Figure S2). Ploidy of neoplastic hemocytes in mussels with MtrBTN2 alleles from the Sea of Japan (range 4.3-4.9n) was on average lower than that in mussels from the Sea of Okhotsk (4.8-5.8n) (Table 1). These differences were statistically significant at $\mathrm{p}=0.05$ (the two-sample Kolmogorov-Smirnov test calculated in PAST; Hammer et al. 2001). In a similar comparison between all cancers from two samples, the differences were insignificant.

Four mussels were selected for detailed analysis by molecular cloning. They were M1-95 and M2-22, which presumably had MtrBTN1, and M1-105 and M1-162, which presumably had MtrBTN2 with different COI alleles. 
Results of molecular cloning are summarized in Supplementary Table S1 (list of all sequences detected), Supplementary Figure S4 (TCS haplotype network of all sequences) and Table 3 (frequencies of common alleles). Nucleotide sequences of alleles found in this study are available at NCBI GenBank (Accession numbers MZ724668-MZ724679 for COI, MZ751085- MZ751090 for CR and MZ751091-MZ751101 for EF1 $\alpha$, Supplementary Table S2).

Cloning confirmed the preliminary diagnosis based on direct COI sequencing. At EF1 $\alpha$, M1-105 and M1-162 bore known combinations of unique MtrBTN2 alleles (G and H) while M2-22 and M95 bore known combinations of unique MtrBTN1 alleles (R and S). At mitochondrial loci, different characteristic MtrBTN2 haplotypes were identified in M1-162 (COI-1, CR-1) and M1-105 (COI-2, CR-2). M2-22 and M1-95 were marked by a combination of COI-U1 and CR-Z1 alleles, CR-Z1 differing by two substitutions from the characteristic CR-Z of BTN1. (To remind, we do not consider here the variation at the polyA region of $\mathrm{CR}$ as putatively artefactual; information on this issue is provided in the Supplementary Table S3). M2-22, M1-95 and M1-162 were seemingly trisomic at EF1 $\alpha$ due to the "additional", relatively rare R1 (M2-22, M95) or H1 (M1-162) alleles, differing by one substitution from the common $\mathrm{R}$ and $\mathrm{H}$ alleles, respectively (Table 3 ). This extra variation could be explained by methodical artefacts of cloning or by somatic mutations in aneuploid cancers. Aneuploidy also could explain the misbalance between common cancerous EF1 $\alpha$ alleles: R allele was represented by more clones than S allele in MtrBTN1 (noted also by Metzger et al. 2016) and G allele was represented by more clones than H allele in MtrBTN2 (Supplementary Figure S4). Other alleles identified were unrelated to cancerous ones and were usually more common in the foot tissues than in the hemolymph (Supplementary Figure S4; Table 3). These alleles evidently represented mussel host genotypes.

Salient features of transmissible cancers of mussels from the Sea of Okhotsk against the background of their global diversity can be seen in phylogenies in Figure 4. MtrBTN2 mtDNA genotypes from the Sea of Okhotsk were nearly identical to those from the Sea of Japan. In particular, both samples were polymorphic for two diverged haplolineages marked by combinations of COI-1+CR-1 and COI-2+CR2 alleles. These Northwest Pacific populations were different from European, Argentinian and Chilean ones. The macro-geographical variability of MtrBTN2 has been discussed in detail in Yonemitsu et al. 2019 and in Skazina et al. 2021. In brief, two distinct CR alleles similar to CR-1 and CR-2 from the Northwest Pacific (CR-D and CR-C by classification of Yonemitsu et al. 2019, respectively) were observed elsewhere, in presumably heteroplasmic (Argentine, both alleles detected in the same cancerous mussels) or homoplasmic (CR-C in Chile and CR-D in Europe) states. COI diversity in Europe and Argentina was considerably lower than in the Northwest Pacific. Chilean MtrBTN2 samples were the most distinctive because their COI alleles were more related to M. chilensis than to 


\begin{tabular}{|c|c|c|c|c|c|c|}
\hline \multirow{2}{*}{\begin{tabular}{|l|} 
Locus \\
Tissue
\end{tabular}} & \multicolumn{2}{|c|}{ EF1 $\alpha$} & \multicolumn{2}{|c|}{$\mathrm{COI}$} & \multicolumn{2}{|c|}{$\mathrm{CR}$} \\
\hline & Foot & Hemo & Foot & Hemo & Foot & Hemo \\
\hline \multicolumn{7}{|l|}{ M2-22 } \\
\hline $\begin{array}{l}\mathrm{N} \\
\text { colonies }\end{array}$ & 16 & 17 & 30 & 26 & 16 & 17 \\
\hline $\begin{array}{l}\text { Major } \\
\text { alleles }\end{array}$ & $\begin{array}{l}\mathbf{R}(9), \mathbf{R} 1(2), \\
\mathbf{S}(5)\end{array}$ & $R(6), S(3)$ & $\begin{array}{c}\text { U1(25), } \\
12(2)\end{array}$ & U1(25) & $\mathbf{Z 1}(12)$ & Z1(17) \\
\hline \multicolumn{7}{|l|}{ M1-95 } \\
\hline $\begin{array}{l}\mathrm{N} \\
\text { colonies }\end{array}$ & 18 & 16 & 30 & 25 & 22 & 28 \\
\hline $\begin{array}{l}\text { Major } \\
\text { alleles }\end{array}$ & $\begin{array}{l}\text { 10(8), R(2), } \\
\text { R1(1), S(2) }\end{array}$ & $\begin{array}{l}\text { R(9), R1(2), } \\
\mathbf{S}(4)\end{array}$ & $\mathbf{U 1}(2), 9(18)$ & U1(28) & $\mathbf{Z 1}(\mathbf{2}), 9(10)$ & $\mathbf{Z 1}(27)$ \\
\hline \multicolumn{7}{|l|}{ M1-105 } \\
\hline $\begin{array}{l}\mathrm{N} \\
\text { colonies }\end{array}$ & 23 & 17 & 30 & 34 & 24 & 18 \\
\hline $\begin{array}{l}\text { Major } \\
\text { alleles }\end{array}$ & $\begin{array}{c}\mathbf{G}(\mathbf{1}), \mathbf{H}(\mathbf{2}) \\
11(5) \\
12(10)\end{array}$ & $\mathbf{G}(15), \mathbf{H}(2)$ & $\mathbf{2 ( 1 )}, 12(27)$ & 2(29), 12(1) & $10(19)$ & $2(16)$ \\
\hline \multicolumn{7}{|l|}{ M1-162 } \\
\hline $\begin{array}{l}\mathrm{N} \\
\text { colonies }\end{array}$ & 21 & 20 & 31 & 33 & 25 & 29 \\
\hline $\begin{array}{l}\text { Major } \\
\text { alleles }\end{array}$ & $\begin{array}{l}13(4), \\
14(10)\end{array}$ & $\begin{array}{c}\mathbf{G}(\mathbf{5}), \mathbf{H}(\mathbf{1}) \\
\mathbf{H} 1(3)\end{array}$ & $8(26)$ & 1(19), 8(9) & $\mathbf{1 ( 5 )}, 11(13)$ & $1(25)$ \\
\hline
\end{tabular}

M. trossulus. MtrBTN1 genotypes from Magadan differed from those from the British Columbia ones by 1-2 substitutions at mitochondrial loci and an "additional" R1 allele at EF1 $\alpha$.

Table 3. Sequences detected by molecular cloning in this study. The number of colonies with corresponding sequence is given in brackets. Sequence names shown in bold corresponds to cancerous alleles.

\section{Discussion}


possibilities of developing rapid tests for BTN based on direct COI sequencing as well as cytological differences and similarities between MtrBTN1 and MtrBTN2.

Geographical and climatic limits of MtrBTN distribution. Our finding of transmissible cancer in mussels collected near Magadan extended the known distribution of this disease into the Pacific Subarctic. It is too early to judge about its overall geographical distribution because many regions such as the eastern coast of North America and Northern Europe have not been surveyed. Nevertheless, the available data on the geographical and temperature boundaries of $M t r B T N$, which are summarized in Figure 1, allow us to draw some preliminary conclusions about the temperature preferences at least of MtrBTN2, which is much more widespread than MtrBTN1.

Similarly to its hosts, the blue mussels themselves, MtrBTN2 survives across almost the entire temperature range of temperate seas, including subpolar seas with strong (Magadan, in M. trossulus, region 9 in Figure 1) and weak (Beagle Strait, in M. chilensis, region 1 in Figure 1) seasonality. In the warmest place where it has been found (Adriatic, in M. galloprovincialis, region 7 in Figure 1), it tolerates temperature regimes unacceptable for its parental species, $M$. trossulus, which is boreal and requires temperatures below $17^{\circ} \mathrm{C}$ to maintain a positive scope for growth (Fly and Hilbish 2013). In the Adriatic Sea, the sea surface temperatures (SST) are above this limit for most of the year (Figure 1B). How far northwards MtrBTN spreads and whether it is present in the Arctic remain an open question. Based on the available data, it cannot be ruled out that the spread of the deadly MtrBTN is not limited by either climate or geography and that any mussel population is potentially at risk.

Genetic features of MtrBTN in the Northwest Pacific. The material on MtrBTN1 is very limited, being represented by two tiny samples from the opposite coasts of the Northeastern Pacific (three cancers from Canada studied by Metzger et al. 2016, and two from Russia, Figure 4). Based on this material, we can only acknowledge minor qualitative differences between these cancers, namely, that they differ by one substitution at COI fragment ( $0.16 \%$ net divergence), by two substitutions at CR fragment $(0.32 \%)$ and by the presence of an "additional" EF1 $\alpha-\mathrm{R} 1$ allele in cancers from Magadan. However, this apparent trisomia could be an artefact of the genotyping method.

The spectrum of MtrBTN2 genotypes from the Sea of Okhotsk (this study) was the same as in the Sea of Japan (Figure 4). It is likely that the cancers from these two seas represent the same broad geographic population. If so, there is little to add to the discussion of macrogeographic variability of MtrBTN2 provided in our previous paper (Skazina et al. 2021). One noteworthy fact is that MtrBTN2 from the Northwest Pacific, on the one hand, and MtrBTN2 from invasive populations of Argentina and Western Europe, on the other hand, show relatively high levels of COI net divergence (0.95-1.27\% vs $0.1-0.3 \%$ between Argentina and Europe, Figure 4). This observation may imply that the Northwest 
Pacific was not the direct source of the invasion. Other possible explanations are a long history of invasive populations or a high mutability of mtDNA.

Based on our data, we may now answer the question whether Northwest Pacific MtrBTN2 is homoplasmic or heteroplasmic by two diverged haplolineages marked by combinations of COI-1+CR1 and COI-2+CR-2 alleles. Yonemitsu et al. 2019 identified both diverged CR alleles (similar to CR-1 and CR-2) in all the three cancerous mussels from Argentina studied by molecular cloning and showed using qPCR that the levels of two alleles could be very different. Based on these results, it was suggested that the homoplasmy by these alleles observed in other populations, also in the Sea of Japan, may be a seeming one, the minor allele eluding molecular cloning (Yonemitsu et al. 2019; Skazina et al. 2021).

In this study we sequenced numerous colonies with CR and COI from two mussels with MtrBTN2 from Magadan (in total 416) and four mussels from the Sea of Japan involved in our previous study. We are inclined to conclude that they are homoplasmic after all. The observed heteroplasmy of MtrBTN2 in Argentina may be due to double infection of mussels with MtrBTN2 clones marked by different CR haplotypes or by somatic hybridization (cell fusion) between these clones. We believe that at least three different clones of MtrBTN (one clone of MtrBTN1 and two clones of MtrBTN2) are parasitizing mussels in Magadan.

An unusually high MtrBTN diversity in Magadan may be a matter of chance. Magadan is a port city, and infection could have been brought there by mussel-fouled ships from anywhere. On the other hand, Magadan is in the heart of the ancestral range of $M$. trossulus in the Northwest Pacific. $M$. trossulus populations in the Sea of Okhotsk are very abundant (Ushakov 1953; Khalaman et al. 2020) and presumably old. They might well turn out to be the natural reservoir of M. trossulus-derived transmissible cancers. Skazina et al. 2021 suggested that the Northwest Pacific may be a natural reservoir of MtrBTN2. Now we can propose the same hypothesis for MtrBTN1.

Rapid test for BTN. A high labour-intensity of the methods used to diagnose MtrBTN is the main reason why so little is known about the diversity and geographic distribution of this disease and about its prevalence in mussel populations. So far, only Hammel et al. (2021) have tried to address these issues comprehensively. They have identified $M t r$ BTN genotypes in a large sample of mussels $(M$. edulis, M. galloprovincialis and their hybrids) from Western Europe with the help of multilocus SNP genotyping using KASP (Kompetitive Allele Specific PCR). This method, based on competition of fluorescence of the two alleles, makes possible a quantitative assessment of the proportion of alternative alleles at a locus in a tissue sample. Chimeric genotypes of cancerous mussels are betrayed by an imbalanced proportion of the alleles, differing from that expected for homo- and heterozygotes. 
This method is especially efficient for identification of MtrBTN (which has the genotype of $M$. trossulus) in mussel species other than $M$. trossulus and also if many taxonomically informative markers are employed such as the SNP set used by Hammel et al. 2021. For KASP genotyping to be effective in the search for MtrBTN in M. trossulus populations, more diagnostic markers for the cancer are needed.

In this study we used a rapid test of BTN based on parallel COI genotyping of the hemolymph and the muscle tissues. This method, though probably less sensitive than that employed by Hammel et al. (2021), is also less expensive. The test did not reveal known MtrBTN alleles in the mussels with a rate of aneuploid cells less than $15 \%$ (Table 1). So, the suggested limit of its sensitivity is $15 \%$ of aneuploid cells in the hemolymph of a MtrBTN-infected mussel.

The test demonstrated both heteroplasmy and its tissue-specific patterns in all mussels with MtrBTN alleles except the most severely infected one (M2-22, 99\% of aneuploid cells), which lacked the host alleles altogether. This means that not only known but also unknown cancerous alleles may potentially be detected using this test. We emphasize that a parallel analysis of the two tissues also makes it possible to distinguish between the cases of heteroplasmy related to chimerism due to BTN and the cases unrelated to it. In the former cases, the test would reveal differences between the foot and the hemolymph tissues, while in the latter cases, such as natural heteroplasmy or NUMTs coamplification, it is unlikely that any such differences would be found.

Two mussels (M1-167 and M1-96) were a stumbling block in the interpretation of the test results. They had a high proportion of aneuploid cells in the hemolymph, no known cancerous alleles and no signs of genetic chimerism. Theoretically, these mussels could be infected by BTN lineages with mutations in the COI universal primers binding sites, which prevent its amplification. Alternatively, they may have conventional (non-transmissible) DN. Mussels with DN but without evidence of genetic chimerism have been repeatedly reported in MtrBTN studies (Metzger et al. 2016; Burioli et al. 2019; Yonemitsu et al. 2019; Hammel et al. 2021). Hammel et al. 2021 made a special effort to prove that mussels can be affected with non-transmissible DN. Unfortunately, we did not study M1-167 and M196 for other markers and did not perform their molecular cloning. We do consider it likely that they had conventional DN, but this diagnosis is preliminary.

Comparison between cancers. Different cancers of mussels from Magadan were quite similar in terms of ploidy (range 4.0-5.8n) and NCR (range of mean values 1.8-2.1). There were several genetic types of DN in our sample (supposedly non-transmissible neoplasia, MtrBTN1 and two distinct clones of MtrBTN2 marked by different COI haplotypes), and each type was represented by a few cases. The ranges of ploidy and NCR for these different DN types overlapped to a large extent. However, the 
407

408

409

410

411

412

413

414

415

416

417

418

419

420

421

422

423

424

425

426

427

428

429

430

431

432

433

434

\section{${ }_{435}$ Author Contributions} mussels (Table 1, 2, Supplementary Figure S2). etiology of the disease is uncertain.

ploidy of MtrBTN2 in the Sea of Japan was somewhat lower (range 4.3n-4.9n) than in the Sea of Okhotsk (range 4.8n-5.8n). Interestingly, the two cases of presumably non-transmissible neoplasia were the most unusual in all the material; more interesting still, they were unusual for different reasons. In M1-167 the ploidy of the cancer cells was the lowest and strictly equal to four, which corresponds to tetraploidy. In M1-96, the cancer cells were noticeably smaller than in the other

The relative uniformity of DN from the Sea of Okhotsk is especially noticeable when compared with the available data on DN in M. edulis from Western Europe, where MtrBTN2 occurs, and in $M$. trossulus from the Northeastern Pacific, where MtrBTN1 was registered. The survey of Burioli et al. (2019) showed that in Europe the ploidy of neoplastic cells varied in different cancerous mussels in the range of 8.36-18.8n; out of the two genetically confirmed cases of MtrBTN, one had a ploidy of 8.4n and the other, with two peaks of aneuploid cells, 9.5n and 11.4n. They also observed that in different mussels the size of the nucleus of the neoplastic cells correlated positively with their ploidy. Hammel et al. (2021) compared genetically confirmed cases of MtrBTN2 and conventional cancer from Europe (the transmissible and non-transmissible cancers were from different populations) on histological slides and recorded differences in the size of the nuclei, with the nuclei being about $40 \%$ larger in the transmissible cancers. In Northeastern Pacific (Washington and British Columbia), earlier studies reported tetraploid and pentaploid cancers (Elston et al. 1990; Moore et al. 1991), while a later study (Vassilenko and Baldwin 2014) reported a range of ploidy 1.4-5.5n of neoplastic cells between cancerous mussels and also within some mussels. As these studies preceded the discovery of BTN, the

Thus, the ranges of ploidy values in mussels with neoplasia from Europe (MtrBTN2-infected populations of $M$. edulis) and from Northeastern Pacific (MtrBTN1-infected populations of $M$. trossulus) do not overlap, though in both regions the range is fairly broad. The range of ploidy values in mussels with neoplasia from Magadan (both lineages in M. trossulus, indistinguishable by ploidy) is narrow and almost overlaps with that of mussels in the Northeastern Pacific. A possible explanation of the 'conservatism' of cancers from the Sea of Okhotsk might be that the ploidy of MtrBTN is controlled not only by its own genotype but also by the genotype of the host and its environment.

M.S., N.O. and P.S. designed the study. K.R. organized mussel sampling M.M., L.F. and N.O. provided cytological and histological analyses. M.S. and I.D. provided molecular genetic analyses. 
M.S. carried out the bioinformatics analysis. M.S. and P.S. drafted the manuscript. All authors read, approved, and contributed to the final manuscript.

\section{Acknowledgments}

We would like to thank Natalia Lentsman for English language editing of the manuscript and Anna Romanovich, Alexey Masharskiy, Dmitriy Samulenkov, Dmitriy Zaitsev and Tatyiana Zemskova (St. Petersburg State University Research Park) for technical help.

\section{Funding details}

This study was supported by the Russian Science Foundation, Grant Number 19-74-20024.

\section{Conflict of Interest}

The authors declare that all authors have no conflict of interest.

\section{Literature}

Aktipis CA, Boddy AM, Jansen G, Hibner U, Hochberg ME, Maley CC, Wilkinson GS (2015) Cancer across the tree of life: Cooperation and cheating in multicellularity. Philos Trans R Soc B Biol Sci. doi: 10.1098/rstb.2014.0219

Barber BJ (2004) Neoplastic diseases of commercially important marine bivalves. Aquat Living Resour 17:449-466. doi: 10.1051/alr:2004052

Bower SM (1989) The Summer Mortality Syndrome and Hemocytic Neoplasia in Blue Mussels Mytilus edulis from British Columbia Canada. Can Tech Rep Fish Aquat Sci 1703:1-65.

Bradley RD, Hillis DA (1997) Recombinant DNA Sequences Generated by PCR Amplification. Mol Biol Evol 14:592-593.

Bramwell G, Schultz AG, Sherman CDH, Giraudeau M, Thomas F, Ujvari B, Dujon AM (2021) A review of the potential effects of climate change on disseminated neoplasia with an emphasis on efficient detection in marine bivalve populations. Sci Total Environ 775:145134. doi: 10.1016/j.scitotenv.2021.145134

Burioli EA V, Trancart S, Simon A, Bernard I, Charles M, Oden E, Bierne N, Houssin M (2019) Implementation of various approaches to study the prevalence, incidence and progression of disseminated neoplasia in mussel stocks.

Carballal MJ, Barber BJ, Iglesias D, Villalba A (2015) Neoplastic diseases of marine bivalves. J Invertebr Pathol 131:83-106. doi: 10.1016/j.jip.2015.06.004

Ciocan C, Sunila I (2005) Disseminated neoplasia in blue mussels, Mytilus galloprovincialis, from the 
Clarke LA, Rebelo CS, Gonçalves J, Boavida MG, Jordan P (2001) PCR amplification introduces errors into mononucleotide and dinucleotide repeat sequences. J Clin Pathol - Mol Pathol 54:351353. doi: 10.1136/mp.54.5.351

Clement M, Snell Q, Walker P, Posada D, Crandall K (2002) TCS: Estimating Gene Genealogies.

Elston R, Drum A, Allen S (1990) Progressive development of circulating polyploid cells in Mytilus with hemic neoplasia. Dis Aquat Organ 8:51-59. doi: 10.3354/dao008051

Elston RA, Moore JD, Brooks K (1992) Disseminated neoplasia of bivalve mollusks. Rev Aquat Sci 6:405-466.

Farley CA (1969) Sarcomatoid proliferative disease in a wild population of blue mussels (Mytilus edulis). J Natl Cancer Inst 43:509-516. doi: 10.1093/jnci/43.2.509

Farley CA, Plutschak DL, Scott RF (1991) Epizootiology and distribution of transmissible sarcoma in Maryland softshell clams, Mya arenaria, 1984-1988. Environ Health Perspect 90:35-41. doi: $10.2307 / 3430843$

Feder HM, Norton DW, Geller JB (2003) A Review of Apparent 20th Century Changes in the Presence of Mussels Mytilus trossulus and Macroalgae in Arctic Alaska, and of Historical and Paleontological Evidence Used to Relate Mollusc Distributions to Climate Change. Arctic 56:391-407. doi: 10.14430/arctic636

Fly EK, Hilbish TJ (2013) Physiological energetics and biogeographic range limits of three congeneric mussel species. Oecologia 172:35-46. doi: 10.1007/s00442-012-2486-6

Folmer O, Black M, Hoeh W, Lutz R, Vrijenhoek R (1994) DNA primers for amplification of mitochondrial cytochrome c oxidase subunit I from diverse metazoan invertebrates. Mol Mar Biol Biotechnol 3:294-299.

Golikov AN, Gagaev SY, Golikov AA, Potin V V (1998) Bottom biocoenoses of the Kolutchinskaya Bay of the Chukchi Sea. Okeanologiya 38:102-104.

Hammel M, Simon A, Arbiol C, Villalba A, Burioli EAV, Pépin JF, Lamy JB, Benabdelmouna A, Bernard I, Houssin M, Charrière GM, Destoumieux-Garzon D, Welch JJ, Metzger MJ, Bierne N (2021) Prevalence and polymorphism of a mussel transmissible cancer in Europe. Mol Ecol 00:116. doi: $10.1111 / \mathrm{mec} .16052$

Hammer Ø, Harper DAT, Ryan PD (2001) PAST: Paleontological Statistics Software Package for Education and Data Analysis. Palaeontol Electron 4:1-9.

Khalaman V V., Trunova AD, Tridrikh NN, Zharnikov VS, Spiridonov VA (2020) From uniformity to multiplicity: development of a sub-arctic Littoral Mussel Bed in the Sea of Okhotsk. Polar Biol 43:1341-1352. doi: 10.1007/s00300-020-02712-4

Kumar S, Stecher G, Li M, Knyaz C, Tamura K (2018) MEGA X: Molecular Evolutionary Genetics Analysis across Computing Platforms. 35:1547-1549. doi: 10.1093/molbev/msy096

Laakkonen HM, Hardman M, Strelkov P, Väinölä R (2020) Cycles of trans-Arctic dispersal and vicariance, and diversification of the amphi-boreal marine fauna. J Evol Biol 00:1-24. doi: $10.1111 /$ jeb. 13674

Larraín MA, Zbawicka M, Araneda C, Gardner JPA, Wenne R (2018) Native and invasive taxa on the Pacific coast of South America: Impacts on aquaculture, traceability and biodiversity of blue 
mussels (Mytilus spp.). Evol Appl 11:298-311. doi: 10.1111/eva.12553

510

511

512

513

514

515

516

517

518

519

520

521

522

523

524

525

526

527

528

529

530

531

532

533

534

535

536

537

538

539

540

541

542

543

544

545

546

547

548

549

Maiorova MA, Odintsova NA (2015) $\beta$ integrin-like protein-mediated adhesion and its disturbances during cell cultivation of the mussel Mytilus trossulus. Cell Tissue Res 361:581-592. doi: 10.1007/s00441-015-2122-y

McDonald JH, Seed R, Koehn RK (1991) Allozymes and morphometric characters of three species of Mytilus in the Northern and Southern Hemispheres. Mar Biol 111:323-333. doi: 10.1007/BF01319403

Metzger MJ, Villalba A, Carballal MJ, Iglesias D, Sherry J, Reinisch C, Muttray AF, Baldwin SA, Goff SP (2016) Widespread transmission of independent cancer lineages within multiple bivalve species. Nature 534:705-709. doi: 10.1038/nature18599

Metzger MJJ, Reinisch C, Sherry J, Goff SPP (2015) Horizontal transmission of clonal cancer cells causes leukemia in soft-shell clams. Cell 161:255-263. doi: 10.1016/j.cell.2015.02.042

Moore JD, Elston RA, Drum AS, Wilkinson MT (1991) Alternate pathogenesis of systemic neoplasia in the bivalve mollusc Mytilus. J Invertebr Pathol 58:231-243. doi: 10.1016/00222011(91)90067-Z

Odintsova NA (2020) Leukemia-Like Cancer in Bivalves. Russ J Mar Biol 46:59-67.

Paabo S, Irwin M, Wilson C (1990) DNA Damage Promotes Jumping between Templates during Enzymatic Amplification. J Biol Chem 265:4718-4721.

Rawson PD, Harper FM (2009) Colonization of the northwest Atlantic by the blue mussel, Mytilus trossulus postdates the last glacial maximum. Mar Biol 156:1857-1868. doi: 10.1007/s00227009-1218-x

Riquet F, Simon A, Bierne N (2017) Weird genotypes? Don't discard them, transmissible cancer could be an explanation. Evol Appl 10:140-145. doi: 10.1111/eva.12439

Skazina M, Odintsova N, Maiorova M, Ivanova A, Väinölä R, Strelkov P (2021) First description of a widespread Mytilus trossulus-derived bivalve transmissible cancer lineage in M. trossulus itself. Sci Rep 11:1-13. doi: 10.1038/s41598-021-85098-5

Sunila I (1987) Histopathology of mussels (Mytilus edulis L.) from the Tvarminne area, the Gulf of Finland (Baltic Sea). Ann Zool Fennici 24:55-69.

Ushakov P V (1953) Fauna of the Sea of Okhotsk and conditions of its existence.

Vassilenko E, Baldwin SA (2014) Using flow cytometry to detect haemic neoplasia in mussels (Mytilus trossulus) from the Pacific Coast of Southern British Columbia, Canada. J Invertebr Pathol 117:68-72. doi: 10.1016/J.JIP.2014.02.002

Villalba A, Carballal MJ, López C (2001) Disseminated neoplasia and large foci indicating heavy haemocytic infiltration in cockles Cerastoderma edule from Galicia (NW Spain). Dis Aquat Organ 46:213-216. doi: 10.3354/dao046213

Wenne R, Bach L, Zbawicka M, Strand J, McDonald JH (2016) A first report on coexistence and hybridization of Mytilus trossulus and M. edulis mussels in Greenland. Polar Biol 39:343-355. doi: $10.1007 / \mathrm{s} 00300-015-1785-\mathrm{x}$

Wenne R, Zbawicka M, Bach L, Strelkov P, Gantsevich M, Kukliński P, Kijewski T, McDonald JH, Sundsaasen KK, Árnyasi M, Lien S, Kaasik A, Herkül K, Kotta J (2020) Trans-atlantic distribution and introgression as inferred from single nucleotide polymorphism: Mussels Mytilus 
and environmental factors. Genes (Basel). doi: 10.3390/genes11050530

551

552

553

554

555

556

557

558

559

560

561

562

563

564
Wolowicz M, Sokolowski A (2006) Effect of eutrophication on the distribution and ecophysiology of the mussel Mytilus trossulus (Bivalvia) in southern Baltic Sea (the Gulf of Gdansk). Limnol Oceanogr 51:580-590.

Yonemitsu MA, Giersch RM, Polo-Prieto M, Hammel M, Simon A, Cremonte F, Avilés FT, MerinoVéliz N, Burioli EA, Muttray AF, Sherry J, Reinisch C, Baldwin SA, Goff SP, Houssin M, Arriagada G, Vázquez N, Bierne N, Metzger MJ (2019) A single clonal lineage of transmissible cancer identified in two marine mussel species in South America and Europe. Elife 8:1-21. doi: 10.7554/eLife. 47788

Zbawicka M, Wenne R, Burzyński A (2014) Mitogenomics of recombinant mitochondrial genomes of Baltic Sea Mytilus mussels. Mol Genet Genomics 289:1275-1287. doi: 10.1007/s00438-0140888-3

Zouros E (2013) Biparental Inheritance Through Uniparental Transmission: The Doubly Uniparental Inheritance (DUI) of Mitochondrial DNA. Evol Biol 40:1-31. doi: 10.1007/s11692-012-9195-2 


\section{Figure Captions}

Figure 1. Geographical distribution of $M t r \mathrm{BTN}$ and temperature conditions in the regions of its findings. (A) Geographical records of MtrBTN. The colour of the symbols indicates the cancer lineage and the shape indicates the host mussel species. Blue - MtrBTN1, red and violet - MtrBTN2, black MtrBTN1 and MtrBTN2 together, white - only mtDNA evidence of MtrBTN2. Squares - M. chilensis, circles $-M$. trossulus, up-pointing triangle $-M$. edulis, down-pointing triangle $-M$. galloprovincialis, diamond - M. edulis, M. galloprovincialis and their hybrids. Numbers indicate places of MtrBTN findings and data sources: 1 - Beagle Channel, Argentine (Yonemitsu et al. 2019), 2 - Chiloé Island, Chile (Yonemitsu et al. 2019), 3 - West Vancouver, British Columbia, Canada (Metzger et al. 2016), 4 - Atlantic coast from Arcachon Bay to Cherbourg Peninsula, France (Hammel et al. 2021), 5 Wadden Sea, the Netherlands (Hammel et al. 2021), 6 - Gdansk Bay, the Baltic Sea, Poland (Zbawicka et al. 2014; Skazina et al. 2021), 7 - Istrian peninsula, the Adriatic Sea, Croatia (Hammel et al. 2021), 8 - Gulf of Peter the Great, the Sea of Japan, Russia (Skazina et al. 2021), 9 - Nagaev Bay, the Sea of Okhotsk, Russia (this study). (B) Monthly sea surface temperature (SST) in the areas where MtrBTN was reported, after https://seatemperature.info/. Temperature curves for different areas are numbered as in plate A. Data from the following observation points closest to MtrBTN findings were used: 1 - Ushuaia, 2 - Castro, 3 - West Vancouver, 4 - Arcachon, 5 - Harlingen, 6 - Sopot, 7 Rovinj, 8 - Nakhodka, 9 - Magadan. (C) MtrBTN-infected littoral mussels M. trossulus from Magadan. The largest mussels are about $50 \mathrm{~mm}$ in size.

Figure 2. Flow cytometry patterns in the hemolymph of selected mussels from the Sea of Okhotsk. Each mussel is characterised by two diagrams. Dot plot on the left shows cell groups. The size of cells is on the OX axis (forward scatter, "FSC-A") and their granularity on the OY axis (side scatter, "SSCA"). Histogram on the right shows ploidy levels: the level of DAPI fluorescence is on the OX axis ("PB450-A"), the number of events is on the OY axis ("Count"). Relative ploidy levels are given near the peaks. In contrast to the healthy mussel (A - M1-12), an additional population of aneuploid cells (violet peaks and dots) is present in the hemolymph of cancerous mussels (B - M1-95 with MtrBTN1 alleles, C - M1-96 cancerous mussel without MtrBTN alleles, D - M1-162 with MtrBTN2 alleles).

Figure 3. Histological sections of tissues of cancerous individuals stained with hematoxylin-eosin at 40x magnification (on the left) and 100x magnification (on the right). (A) Hemocyte infiltration in the connective tissues between digestive tubes of M1-95 individual infected with BTN1. (B) Hemocytes in the vesicular connective tissue of the gonad (on the left) and between digestive tubes (on the right) of M1-96 individual supposedly having conventional DN. (C) Heavy hemocyte infiltration of gill tissues of M1-105 individual infected by MtrBTN2. (D) Infiltration of connective tissues between digestive tubes of M1-162 individual infected by MtrBTN2. Red arrowheads point to cancerous hemocytes, green arrowheads point to healthy ones. A yellow asterisk marks the sperm cells. Scale bar, $50 \mu \mathrm{m}$.

Figure 4. Phylogenetic analysis of nuclear and mitochondrial loci of mussels with BTN. Maximum likelihood (ML) trees are rooted at the midpoint, bootstrap values below 50 are removed. (A) EF1 $\alpha$ ML tree based on the $630 \mathrm{bp}$ alignment $(\mathrm{HKY}+\mathrm{G})$. (B) COI ML tree based on the $630 \mathrm{bp}$ alignment $(\mathrm{GTR}+\mathrm{G})$. (C) CR ML tree based on the $828 \mathrm{bp}$ alignment $(\mathrm{HKY}+\mathrm{G})$. Branches marked by two slashes are shortened 5-fold for COI and CR. The scale bars mark genetic distance. The analysis is based on 10 diseased mussels from Yonemitsu et al. 2019 (marked by red colour; note that Castro26 host COI allele $\mathrm{J}$ was not included because of the short sequence length), one mitochondrial sequence from the Baltic mussel 62mc10 (Zbawicka et al. 2014, also marked by red colour), four diseased mussels from the Sea of Japan (Skazina et al., 2021; marked by violet colour), and new data on four mussels with DN from the Sea of Okhotsk (marked by black colour). Open circles at the end of branches mark host alleles, closed circles mark cancer alleles. Geographic origin of the samples and species identity of the clades are indicated. 


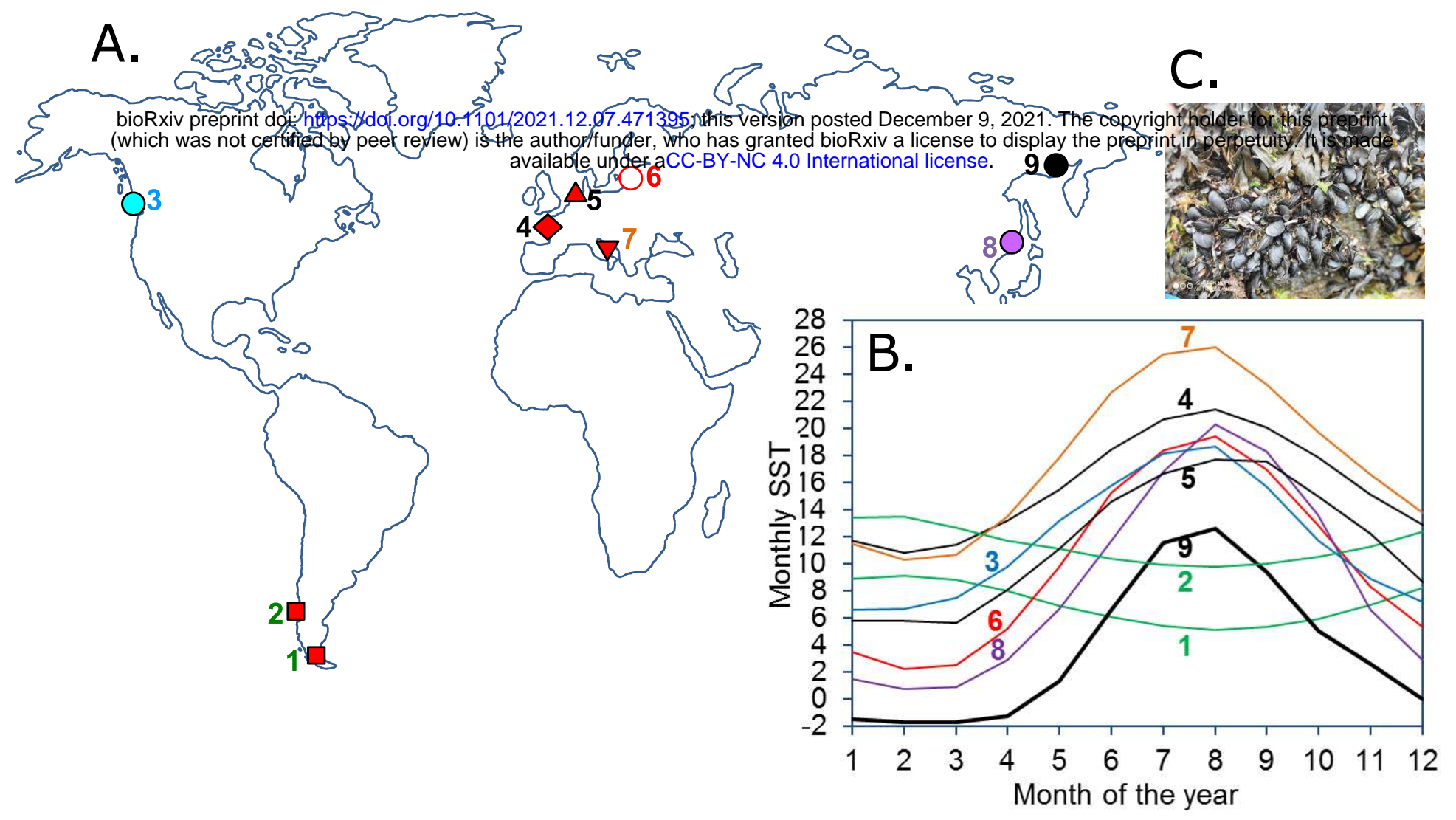




\section{A.}

bioRxiv preprint dol: httpos: $\#$ ddi.org/10.1101/2021.12.07.471395; this version po\$ted December 9, 2021. The copyright holder for this preprint (which was not certified by peer review) is the author/funder, who has granted bioRxiv a license to isplay the preprint in perpetuity. It is made
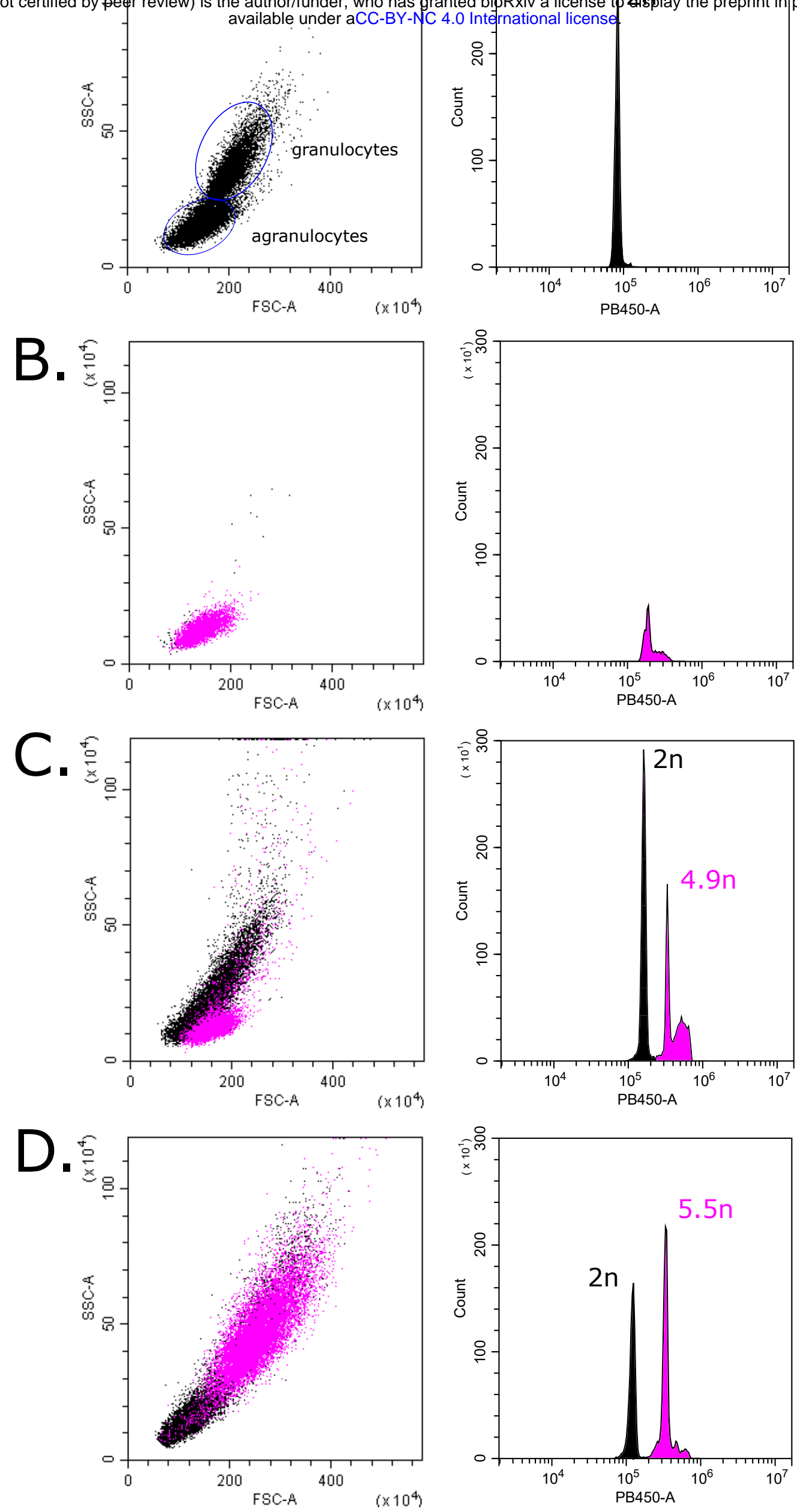


\section{A. M1-95}

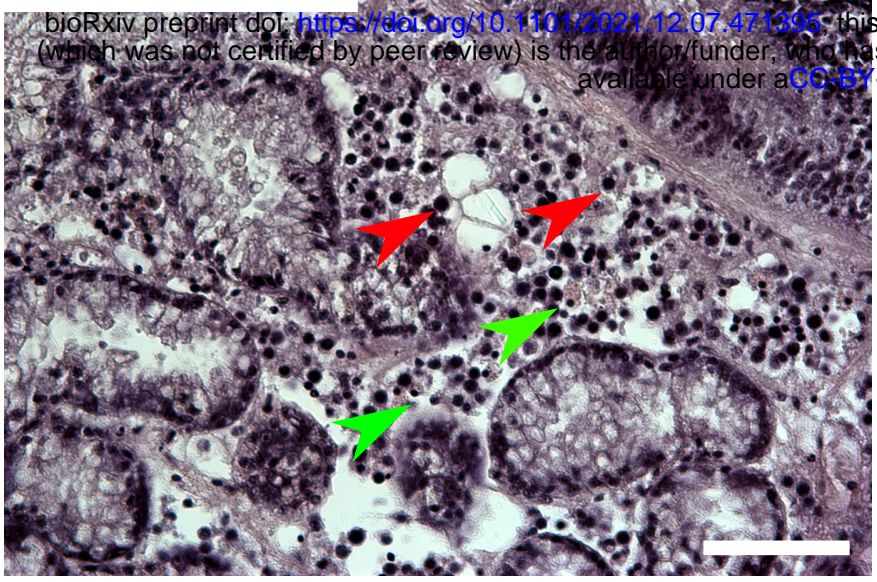

\section{B. M1-96}

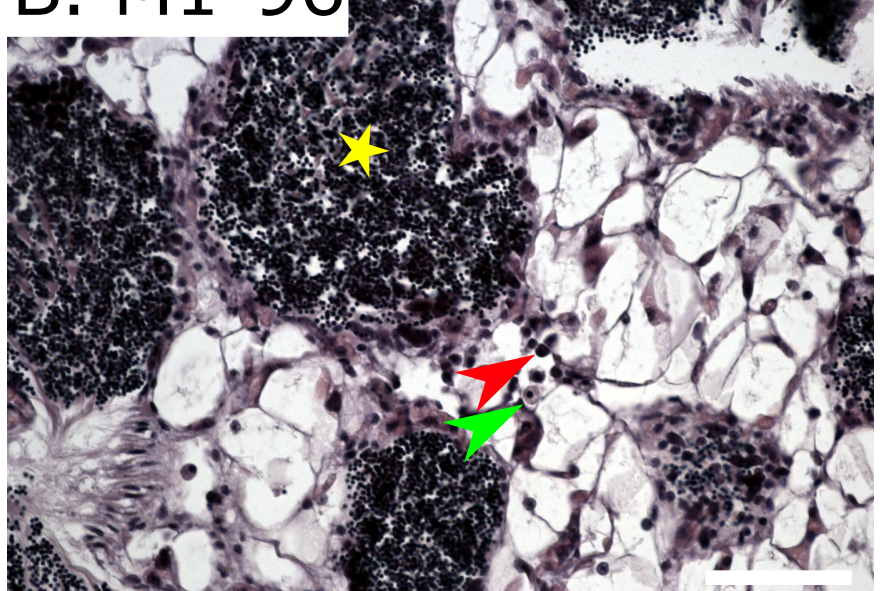

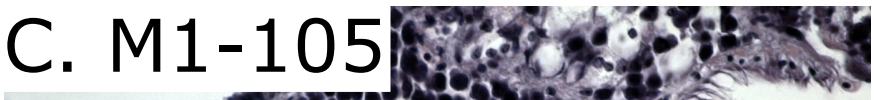
- 150

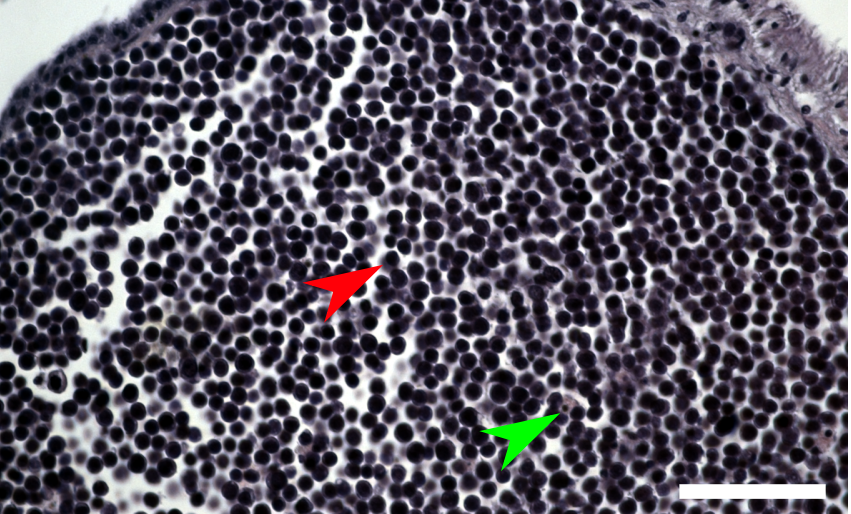

D. $M 1-162 \% \%$ 3.

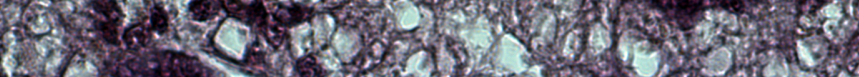

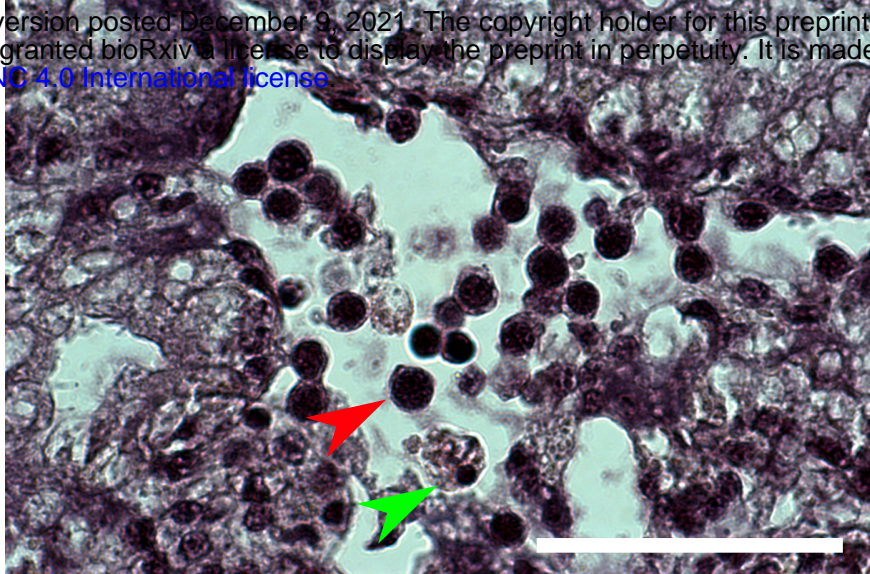
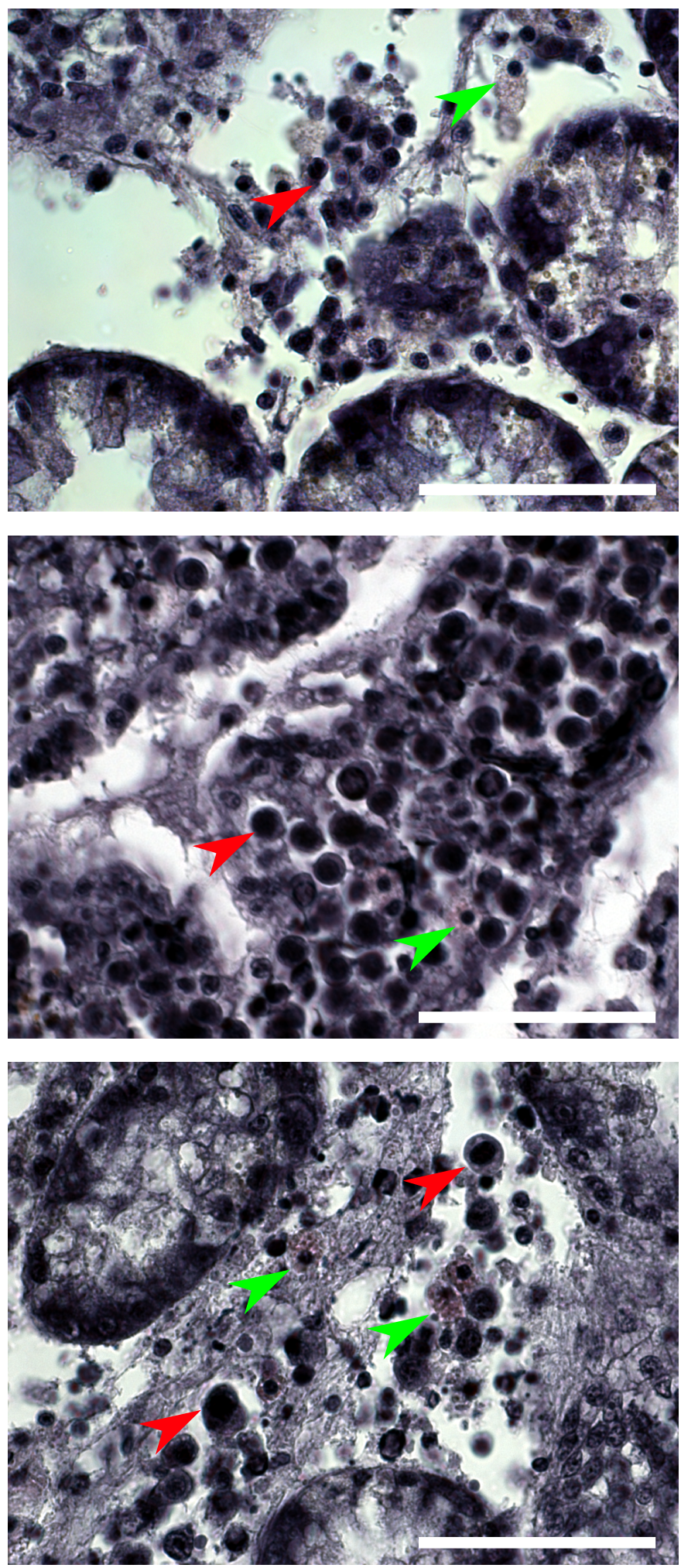
M. edulis 6 . OAR7-R

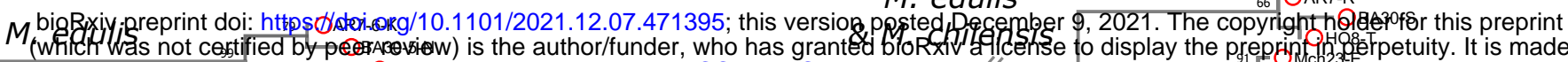

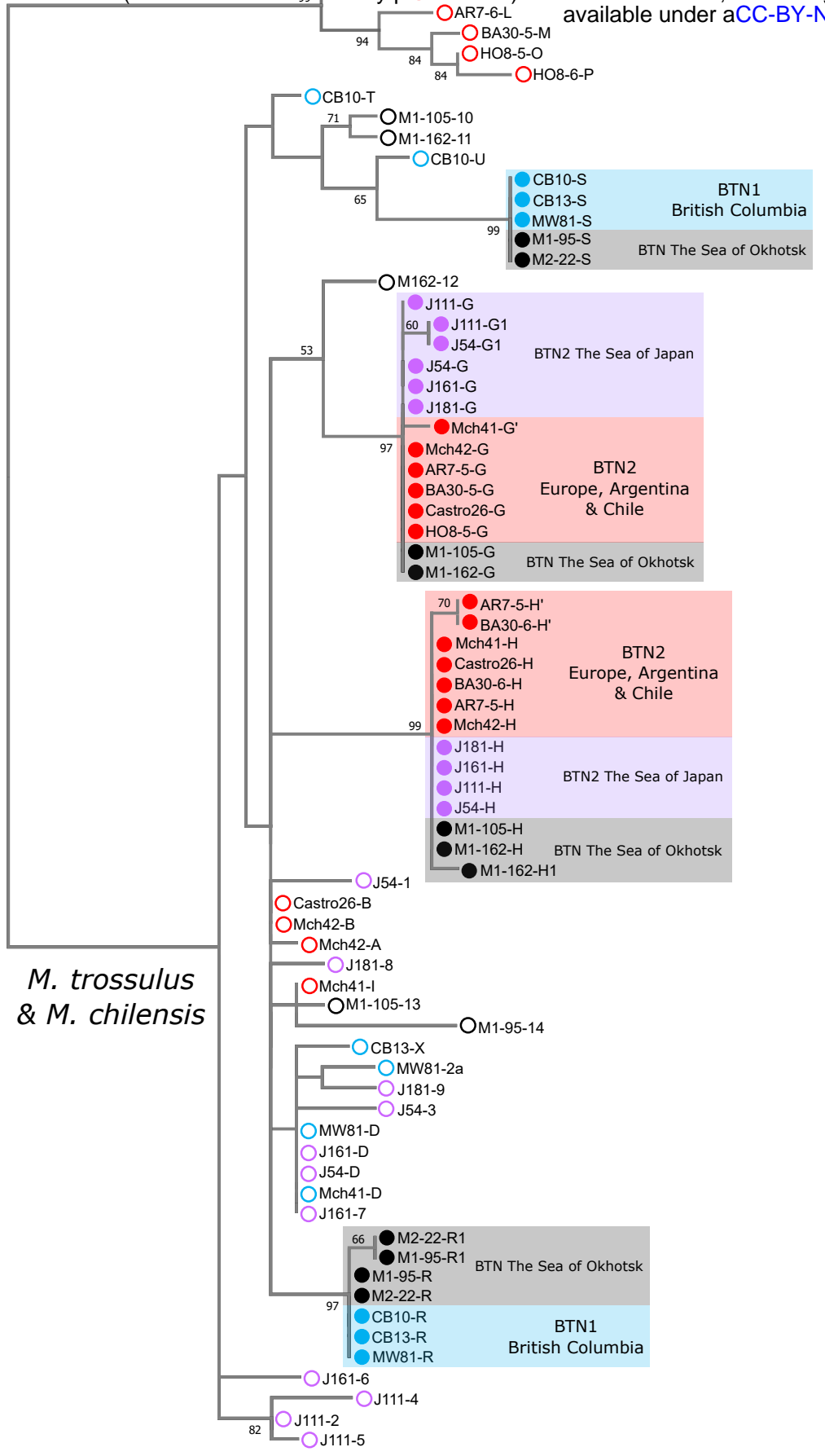

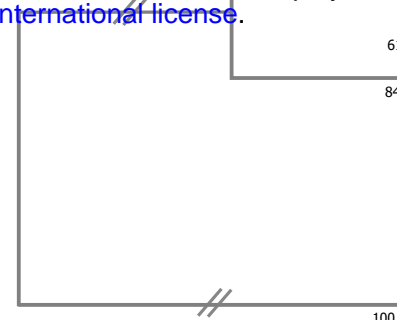

M. trossulus LOCastro52-K OCastro26-1

${ }_{99}$ Castro26-Q BTN2 Chile 4 OMch23-F 91 OMch42-H

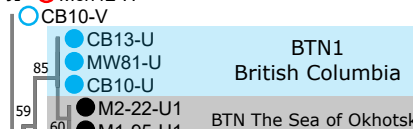
59 60 M2-22-U1 M1-95-U1 BTN The Sea of Okhotsk

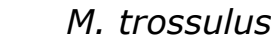
OMW81-X OJ181-6
$-O \mathrm{CB} 13-\mathrm{W}$ OJ111-4

OM2-22-12

${ }_{78} \mathrm{OM} 1-105-12$

IJ $5161-3$

OM1-162-8

${ }_{87}$ M1-162-1 BTN The Sea of Okhotsk 87 \begin{tabular}{l|l}
$\mathrm{M} 1-1$ \\
$\mathrm{~J} 54-1$
\end{tabular} BTN2 The Sea of Japan M1-105-2 BTN The Sea of Okhotsk \begin{tabular}{llll}
\hline & 100 & $J 111-2$ & BTN2 The Sea of Japan
\end{tabular} J J181-2

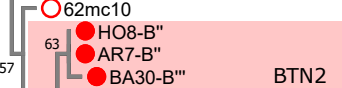
0,050 91 Mch23-B

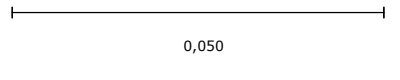

91 Mch41-B Europe \& Argentina

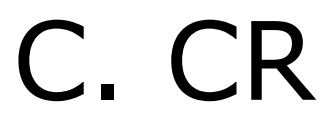

M. edulis

\& M. chilensis
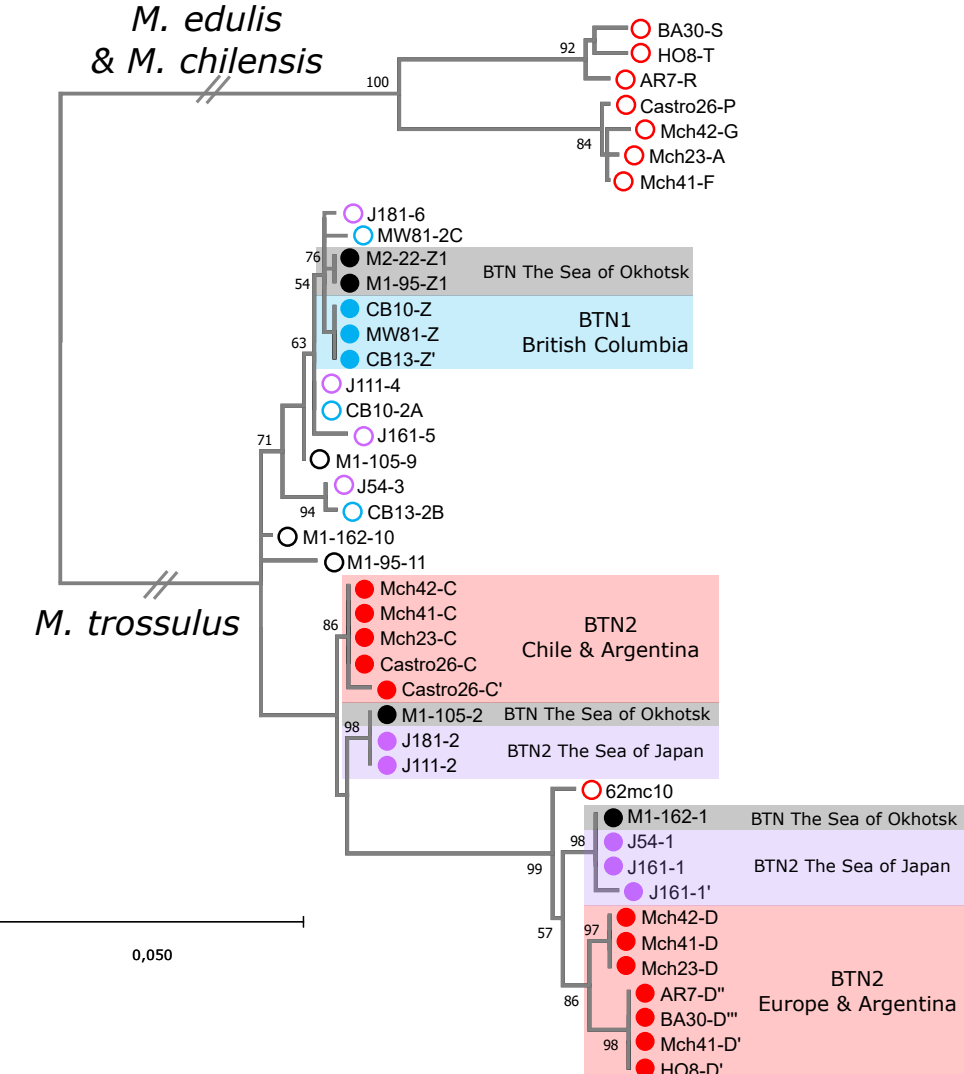